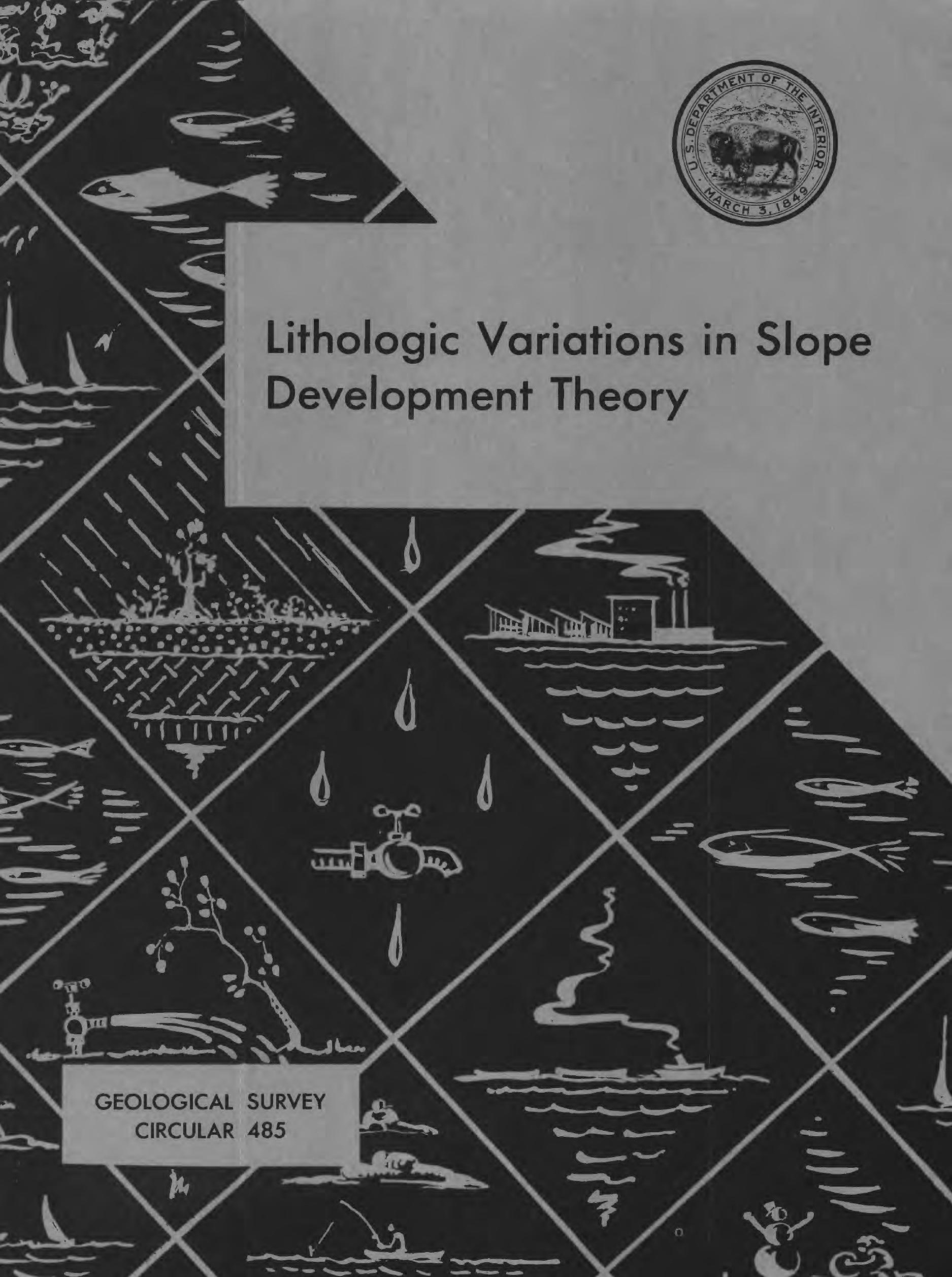




\title{
Lithologic Variations in Slope Development Theory
}

\author{
By Adrian E. Scheidegger
}

父

Geological Survey Circular 485 


\section{United States Department of the Interior}

STEWART L. UDALL, SECRetary

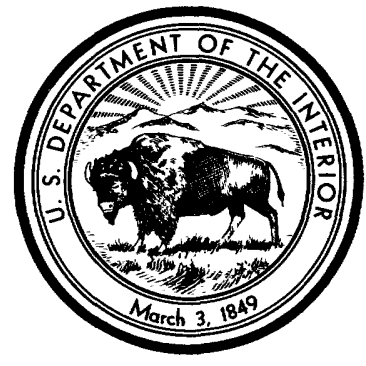

Geological Survey

THOMAS B. NOLAN, Director

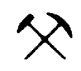

Free on application to the U.S. Geological Survey, Washington, D. C. 20242 


\section{CONTENTS}

Page

\section{1}

Abstract ... 2...

Introduction ..........................

The basic slope program

Slope with-

Caprock ................... Resistant layer
1

2

2

5
Page

Soft layer............ 5

Soft bottom ............. 5

Pore water pressure.... 7

\section{ILLUSTRATIONS}

Figure 1. Graph showing basic slope development

2-6. Graph showing slope with-

2 .

3.

4.

5.

6.
Caprock

Resistant layer

Soft layer

Soft bottom

Pore water pressure

TABLES

Table 1. Basic slope program

2-6. Slope with-

3.

Caprock

4.

Resistant layer

Soft layer

5. Soft bottom

6. Pore water pressure 


\title{
Lithologic Variations in Slope Development Theory
}

\author{
By Adrian E. Scheidegger
}

\begin{abstract}
This paper presents a comprehensive review and amplification of the writer's earlier slope development theory. In particular, the influence of lithology on evolving slope profiles is investigated and calculations are made for various conditions, such as presence of caprock, soft bottom, and hard and soft intermediate layers.
\end{abstract}

\section{INTRODUCTION}

The understanding of the basic principles involved in the development of slopes is crucial for the understanding of the evolution of a landscape.

There are basically two methods by which the development of a slope can be studied. The first is the inductive method, in which measurements in the field are made in the hope to discover regularities which can later be formulated as "laws." In very complex phenomena, this approach may be hopelessly confusing. The second method, the deductive one, considers only one variable at a time, and makes a reasonable assumption regarding the physical principles involved in its change. The consequences of the assumptions are then deduced and, finally, the deductions are tested by determining whether the predicted features are found anywhere in nature. As Wolman (1963) stated: "The emphasis on principles...directs attention to interrelationships and hopefully lessens the tendency to observe, measure, and record everything simply because it is there."

With a view to providing a theoretical basis for work in the field, the writer (Scheidegger, 1961) proposed a simple mathematical model of slope erosion. The aim of the present paper is to elaborate on the earlier procedure by investigating the effect of lithologic variations along the slope profile upon the appearance of the latter, as calculated from the writer's theory.
The basic mathematical slope development model described earlier (Scheidegger, 1961) does not attempt to describe in detail the "microscopic" aspects of erosion; rather, it attempts to describe the overall effect of many contributing causes. It is assumed (a) that the speed with which denudation proceeds is proportional to the declivity of the slope and (b) that the action of the denudation is normal to the tangent of the slope profile. These are very simple assumptions, but it is believed that they may describe some actual phenomena correctly; they lead to a nonlinear partial differential equation.

In the present context, the term "slope" should be regarded in a very general sense. It may refer to a mountainside, to the ungraded part of a headwater stream, or to the profile of a promontory. Under conditions where the aforementioned assumptions are satisfied, the slopes will develop as calculated here. Hopefully, such conditions will be found in nature.

Before proceeding with the investigation of the influence of lithology in slope development theory, the deduction of the original partial differential equation will be recapitulated. In fact, the assumptions denoted by (a) and (b) above immediately lead to

$$
\frac{\partial y}{\partial T}=-\frac{\partial y}{\partial x} \sqrt{1+\left(\frac{\partial y}{\partial x}\right)^{2}}
$$

where $y$ is the vertical height above some base line, $T$ is time, and $x$ is the horizontal abscissa of the slope point under consideration (arbitrary units of $x$ and $y$ ). If a lithological resistance factor $\alpha$ is introduced, the differential equation becomes

$$
\frac{\partial y}{\partial T}=-\alpha(x, y) \frac{\partial y}{\partial x} \sqrt{1+\left(\frac{\partial y}{\partial x}\right)^{2}}
$$


This equation is solved easily on an electronic computer by the same method as that applied to the basic differential equation.

The mathematical solution representing the denudation of an originally straight slope bank for a variety of conditions will be given here. A point of reference also will be provided by reproducing the basic solution $(a=1)$ of the slope problem.

\section{THE BASIC SLOPE PROGRAM}

In order to provide a point of reference for the calculations reported here, the wellknown case for the evolution of a straight slope bank consisting of homogeneous mate rial will be presented first. For conformity with the results to be reported later, the solution of the differential equation has been recalculated for a slope bank with the following initial configuration:

$$
\begin{array}{lll}
y=4^{x} & \text { for } & 0 \leq x \leq 0.25 \\
y=1 & \text { for } & 0.25 \leq x \leq 1.0
\end{array}
$$

The steps in $x$ were in units of 0.01 . The time steps were originally chosen as 0.01 , but these were modified by the computer program to satisfy the criterion of the characteristics. The present computer program has been described in detail previously by the writer (Scheidegger, 1962).
The results of the calculations, which will represent a reference solution, presenting the slope profile for the same time values as will be used later for the further calculations, are shown in table 1 and figure 1. The units for $x$ (horizontal coordinate), y (vertical coordinate), and $T$ (total time elapsed) are arbitrary, and may be so chosen as to suit a particular problem.

\section{SLOPE WITH CAPROCK}

The first modification of the basic slope development problem to be presented is that of a horizontal layer of caprock. This can easily be accomplished by setting in equation 2

$$
\begin{array}{lll}
a=1.0 & \text { for } & 0 \leq y \leq 0.9 \\
a=0.1 & \text { for } & 0.9 \leq y \leq 1.0
\end{array}
$$

Thus, the caprock is 10 times more resistant to being eroded than the body of the slope.

It is again assumed that initially, the slope represents the appearance of a straight slope bank as given by equation 3 . As time proceeds, a characteristic profile develops, as is shown numerically in table 2 and graphically in figure 2 .

The calculated profile is a very good representation of slope profiles that are found in

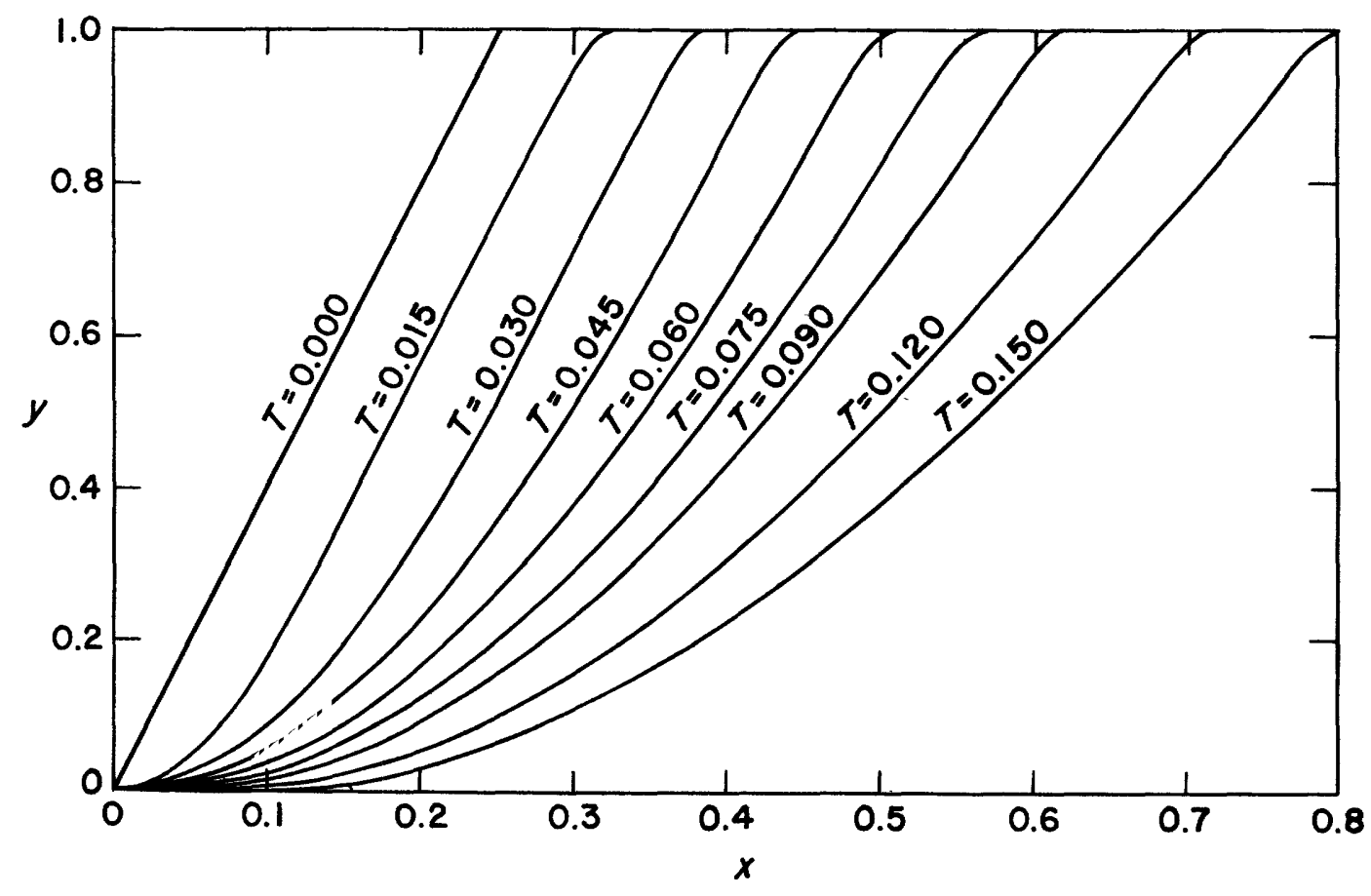

Figure 1. -Graph showing basic slope development. 
Table 1.-Basic slope program

\begin{tabular}{|c|c|c|c|c|c|c|c|c|c|}
\hline$x$ & $T=0.0$ & $T=0.015$ & $T=0.030$ & $T=0.045$ & $T=0.60$ & $T=0.075$ & $\mathrm{~T}=0.90$ & $\mathrm{~T}=0.120$ & $\mathrm{~T}=0.150$ \\
\hline 0.00 & 0 & 0 & 0 & 0 & 0 & 0 & 0 & 0 & 0 \\
\hline .02 & .08 & .010 & .003 & 0 & 0 & 0 & 0 & 0 & 0 \\
\hline .04 & .16 & .035 & .014 & .0058 & .0023 & 0 & 0 & 0 & 0 \\
\hline .06 & .24 & .071 & .032 & .017 & .0085 & .0041 & .0018 & 0 & 0 \\
\hline .08 & .32 & .12 & .058 & .033 & .019 & .011 & .0060 & .0014 & 0 \\
\hline .10 & .40 & .18 & .090 & .054 & .034 & .022 & .013 & .0044 & .0011 \\
\hline .12 & .48 & .24 & .13 & .080 & .053 & .036 & .024 & .0098 & .0033 \\
\hline .14 & .56 & .32 & .17 & .11 & .076 & .053 & .038 & .018 & .0074 \\
\hline .16 & .64 & .39 & .22 & .15 & .10 & .074 & .054 & .028 & .014 \\
\hline .18 & .72 & .47 & .28 & .18 & .13 & .097 & .073 & .041 & .022 \\
\hline .20 & .80 & .55 & .34 & .23 & .16 & .12 & .094 & .056 & .032 \\
\hline .22 & .88 & .63 & .40 & .27 & .20 & .15 & .12 & .073 & .045 \\
\hline .24 & .96 & .71 & .48 & .33 & .24 & .18 & .14 & .092 & .059 \\
\hline .26 & 1.00 & .79 & .55 & .38 & .28 & .21 & .17 & .12 & .074 \\
\hline .28 & & .87 & .63 & .44 & .33 & .25 & .20 & .14 & .092 \\
\hline .30 & & .95 & .71 & .50 & .38 & .29 & .24 & .16 & .11 \\
\hline .32 & & 1.00 & .79 & .57 & .43 & .34 & .27 & .19 & .13 \\
\hline .34 & & 1.00 & .87 & .64 & .48 & .38 & .31 & .21 & .15 \\
\hline .36 & & & .94 & .71 & .54 & .43 & .35 & .24 & .18 \\
\hline .38 & & & 1.00 & .78 & .60 & .48 & .39 & .27 & .20 \\
\hline .40 & & & 1.00 & .86 & .66 & .53 & .43 & .31 & .23 \\
\hline .42 & & & 1.00 & .94 & .73 & .58 & .48 & .34 & .25 \\
\hline .44 & & & & 1.00 & .80 & .64 & .53 & .38 & .28 \\
\hline .46 & & & & 1.00 & .87 & .70 & .58 & .42 & .31 \\
\hline .48 & & & & 1.00 & .94 & .76 & .63 & .46 & .35 \\
\hline .50 & & & & & 1.00 & .82 & .68 & .50 & .38 \\
\hline .52 & & & & & 1.00 & .89 & .74 & .54 & .41 \\
\hline .54 & & & & & 1.00 & .96 & .80 & .58 & .45 \\
\hline .56 & & & & & & 1.00 & .86 & .63 & .49 \\
\hline .58 & & & & & & 1.00 & .92 & .68 & .52 \\
\hline .60 & & & & & & 1.00 & .98 & .73 & .56 \\
\hline .62 & & & & & & & 1.00 & .78 & .60 \\
\hline .64 & & & & & & & 1.00 & .83 & .65 \\
\hline .66 & & & & & & & 1.00 & .88 & .69 \\
\hline .68 & & & & & & & & .94 & .73 \\
\hline .70 & & & & & & & & .99 & .78 \\
\hline .72 & & & & & & & & 1.00 & .83 \\
\hline .74 & & & & & & & & 1.00 & .88 \\
\hline .76 & & & & & & & & 1.00 & .93 \\
\hline .78 & & & & & & & & & .98 \\
\hline .80 & & & & & & & & & 1.00 \\
\hline .82 & & & & & & & & & 1.00 \\
\hline .84 & & & & & & & & & 1.00 \\
\hline
\end{tabular}

nature. If the profile were assumed to be symmetrical with regard to some vertical axis, the form that would evolve would be that of a mesa. 


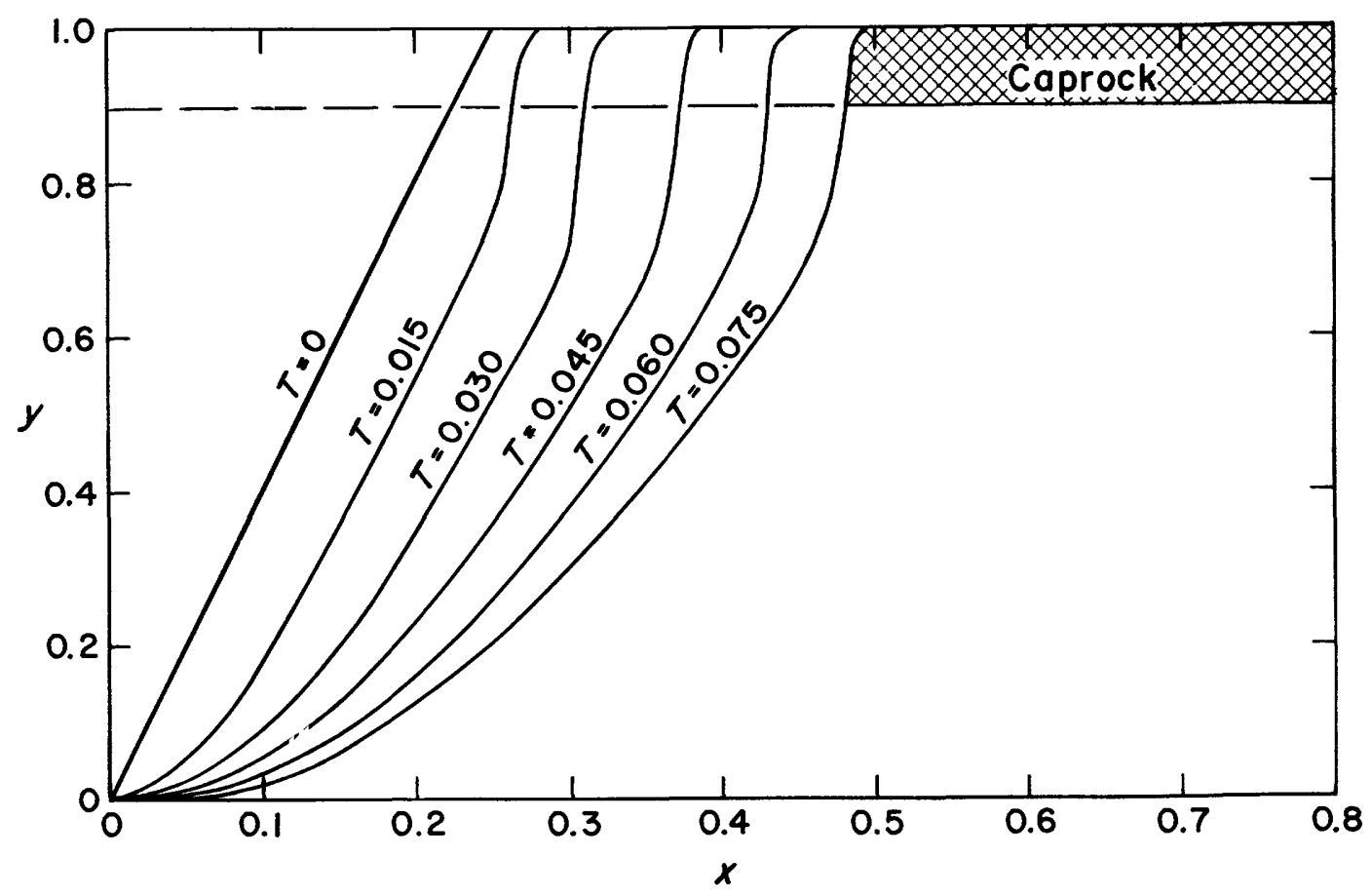

Figure 2. -Graph showing slope with caprock.

Table 2.-Slope with caprock

\begin{tabular}{|c|c|c|c|c|c|c|}
\hline$x$ & $\begin{array}{c}\mathrm{T}=0 \\
(0 \text { steps })\end{array}$ & $\begin{array}{c}T=0.015 \\
(96 \text { steps })\end{array}$ & $\begin{array}{c}T=0.030 \\
(192 \text { steps })\end{array}$ & $\begin{array}{r}T=0.045 \\
(288 \text { steps })\end{array}$ & $\begin{array}{c}T=0.060 \\
(384 \text { steps })\end{array}$ & $\begin{array}{c}T=0.075 \\
(480 \text { steps) }\end{array}$ \\
\hline 0.00 & 0 & 0 & 0 & 0 & 0 & 0 \\
\hline .02 & .080 & .011 & .0031 & 0 & 0 & 0 \\
\hline .04 & .16 & .035 & .014 & .0062 & .0025 & 0 \\
\hline .06 & .24 & .072 & .033 & .017 & .0089 & .0043 \\
\hline .08 & .32 & .12 & .060 & .034 & .020 & .011 \\
\hline .10 & .40 & .18 & .092 & .056 & .035 & .022 \\
\hline .12 & .48 & .24 & .13 & .082 & .055 & .037 \\
\hline .14 & .56 & .32 & .18 & .11 & .077 & .055 \\
\hline .16 & .64 & .39 & .23 & .15 & .10 & .075 \\
\hline .18 & .72 & .47 & .28 & .19 & .13 & .099 \\
\hline .20 & .80 & .55 & .34 & .23 & .17 & .13 \\
\hline .22 & .88 & .63 & .41 & .28 & .20 & .15 \\
\hline .24 & .96 & .71 & .48 & .33 & .24 & .19 \\
\hline .26 & 1.00 & .93 & .55 & .39 & .29 & .22 \\
\hline .28 & 1.00 & 1.00 & .63 & .44 & .33 & .26 \\
\hline .30 & & 1.00 & .72 & .51 & .38 & .30 \\
\hline .32 & & 1.00 & .99 & .57 & .43 & .34 \\
\hline .34 & & & 1.00 & .64 & .49 & .38 \\
\hline .36 & & & 1.00 & .73 & .55 & .43 \\
\hline .38 & & & 1.00 & 1.00 & .61 & .48 \\
\hline .40 & & & & 1.00 & .67 & .53 \\
\hline .42 & & & & 1.00 & .80 & .59 \\
\hline .44 & & & & & 1.00 & .65 \\
\hline .46 & & & & & 1.00 & .71 \\
\hline .48 & & & & & 1.00 & .96 \\
\hline .50 & & & & & & 1.00 \\
\hline
\end{tabular}




\section{SLOPE WITH RESISTANT LAYER}

The influence of a horizontal resistant layer on the shape of a developing slope profile will now be calculated.

The following values for $a$ in equation 2 will be assumed:

$$
\begin{aligned}
& \alpha=0.1 \text { for } 0.4 \leq y<0.5 \\
& \alpha=1.0 \text { for all other values of } y
\end{aligned}
$$

Naturally, the operation begins with a straight slope bank as given in equation, 3 . The results of the calculation are shown numerically in table 3 and graphically in figure 3 .

\section{SLOPE WITH SOFT LAYER}

The reverse condition to that considered in the previous paragraph is that of a slope with a horizontal soft layer. It is assumed that

$$
\begin{aligned}
& a=1.0 \text { for } 0.4 \leq y<0.5 \\
& a=0.1 \text { otherwise }
\end{aligned}
$$

and equation 2 is recalculated for these values of $a$. The results are shown numerically in table 4 and graphically in figure 4 .

\section{SLOPE WITH SOFT BOTTOM}

The condition of a slope with a soft bottom is now considered, and it is assumed that

$$
\begin{aligned}
& \alpha=0.1 \text { for } 0.1 \leq y \\
& \alpha=1.0 \text { for } 0 \leq y<0.1
\end{aligned}
$$

\begin{tabular}{|c|c|c|c|c|c|c|}
\hline$x$ & $\begin{array}{c}T=0 \\
(0 \text { steps })\end{array}$ & $\begin{array}{l}T=0.015 \\
(96 \text { steps })\end{array}$ & $\begin{array}{c}T=0.030 \\
(192 \text { steps })\end{array}$ & $\begin{array}{c}T=0.045 \\
(288 \text { steps })\end{array}$ & $\begin{array}{c}T=0.060 \\
(384 \text { steps })\end{array}$ & $\begin{array}{l}T=0.075 \\
(480 \text { steps })\end{array}$ \\
\hline 0.00 & 0 & 0 & 0 & 0 & 0 & 0 \\
\hline .02 & .080 & .011 & .0031 & 0 & 0 & 0 \\
\hline .04 & .16 & .035 & .014 & .0062 & .0025 & 0 \\
\hline .06 & .24 & .073 & .033 & .017 & .0089 & .0044 \\
\hline .08 & .32 & .12 & .060 & .034 & .020 & .012 \\
\hline .10 & .40 & .18 & .092 & .056 & .035 & $.02 \dot{2}$ \\
\hline .12 & .48 & .25 & .13 & .082 & .055 & .037 \\
\hline .14 & .56 & .48 & .18 & .11 & .077 & .055 \\
\hline .16 & .64 & .52 & .23 & .15 & .10 & .075 \\
\hline .18 & .72 & .56 & .45 & .19 & .13 & .099 \\
\hline .20 & .80 & .60 & .52 & .23 & .17 & .13 \\
\hline .22 & .88 & .66 & .57 & .43 & .20 & .15 \\
\hline .24 & .96 & .73 & .61 & .52 & .25 & .19 \\
\hline .26 & 1.00 & .80 & .66 & .57 & .45 & .22 \\
\hline .28 & 1.00 & .87 & .71 & .62 & .52 & .27 \\
\hline .30 & 1.00 & .95 & .76 & .67 & .57 & .49 \\
\hline .32 & & 1.00 & .82 & .71 & .62 & .53 \\
\hline .34 & & 1.00 & .89 & .76 & .67 & .57 \\
\hline .36 & & 1.00 & .96 & .81 & .72 & .62 \\
\hline .38 & & & 1.00 & .87 & .76 & .67 \\
\hline .40 & & & 1.00 & .93 & .81 & .72 \\
\hline .42 & & & 1.00 & .98 & .86 & .77 \\
\hline .44 & & & & 1.00 & .92 & .81 \\
\hline .46 & & & & 1.00 & .97 & .86 \\
\hline .48 & & & & 1.00 & 1.00 & .91 \\
\hline .50 & & & & & 1.00 & .96 \\
\hline .52 & & & & & 1.00 & 1.00 \\
\hline .54 & & & & & & 1.00 \\
\hline .56 & & & & & & 1.00 \\
\hline
\end{tabular}

This condition is, in a way, the reverse of that representing a slope with caprock. The

Table 3.-Slope with resistant layer 


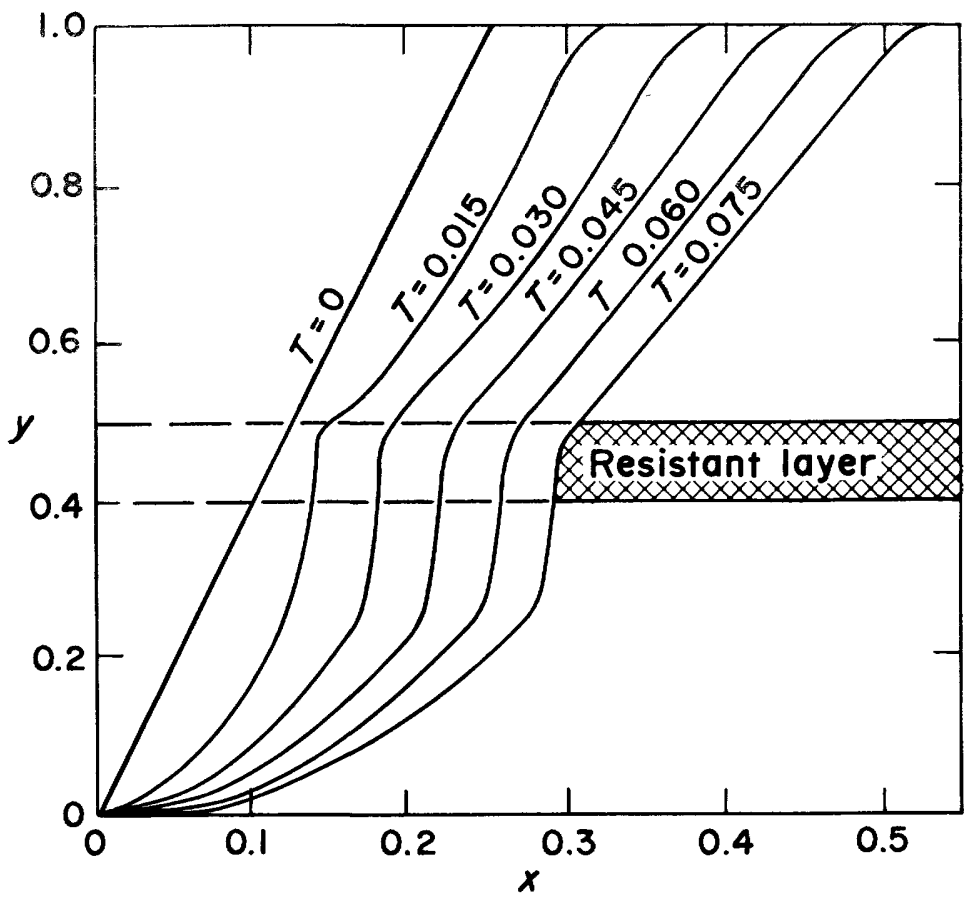

Figure 3.-Graph showing slope with resistant layer.

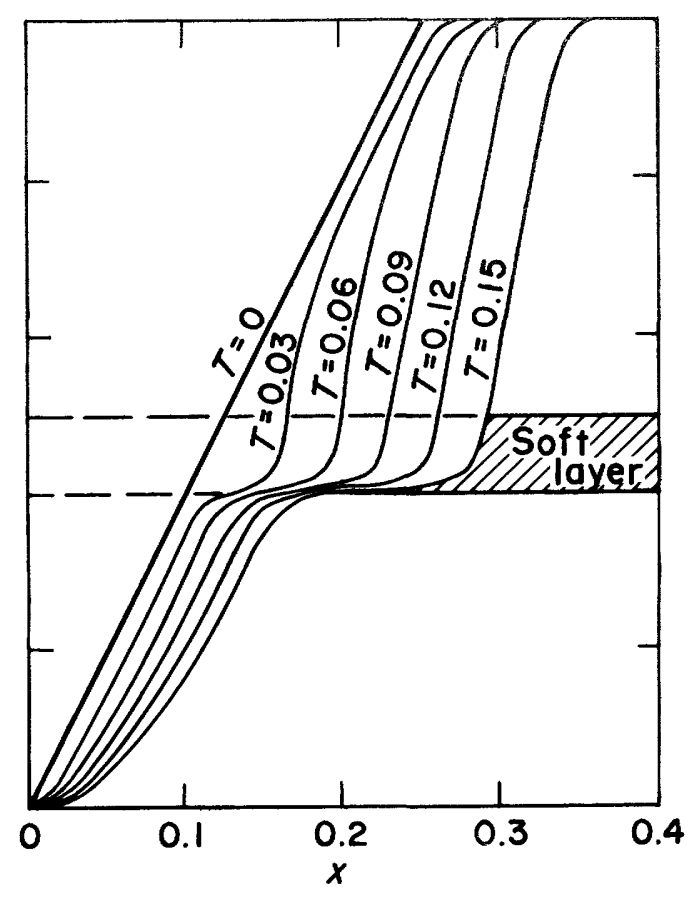

Figure 4. -Graph showing slope with soft layer.

Table 4.-Slope with soft layer

\begin{tabular}{ccccccc}
\hline$x$ & $T=0$ & $T=0.03$ & $T=0.06$ & $T=0.09$ & $T=0.12$ & $T=0.15$ \\
\hline 00 & 0 & 0 & 0 & 0 & 0 & 0 \\
.02 & .080 & .044 & .028 & .020 & .015 & .011 \\
.04 & .16 & .11 & .080 & .060 & .046 & .037 \\
.06 & .24 & .19 & .15 & .11 & .092 & .075 \\
.08 & .32 & .27 & .22 & .18 & .15 & .12 \\
.10 & .40 & .35 & .30 & .55 & .21 & .18 \\
.12 & .48 & .40 & .37 & .33 & .29 & .25 \\
.14 & .56 & .41 & .40 & .39 & .36 & .32 \\
.16 & .64 & .44 & .40 & .40 & .40 & .38 \\
.18 & .72 & .65 & .42 & .40 & .40 & .40 \\
.20 & .80 & .75 & .52 & .41 & .40 & .40 \\
.22 & .88 & .83 & .72 & .43 & .41 & .40 \\
.24 & .96 & .91 & .85 & .61 & .42 & .41 \\
.26 & 1.00 & .98 & .94 & .81 & .50 & .41 \\
.28 & 1.00 & 1.00 & 1.00 & .95 & .70 & .43 \\
.30 & & 1.00 & 1.00 & 1.00 & .89 & .59 \\
.32 & & & & 1.00 & 1.00 & .79 \\
.34 & & & & & 1.00 & .96 \\
.36 & & & & & & 1.00 \\
.38 & & & & & & 1.00 \\
\hline
\end{tabular}


results of the calculations are shown numerically in table 5 and graphically in figure 5.

It is observed that the development of the slope is completely characterized by the decay in the bottom layer, which results in virtually parallel slope recession, the speed of which is determined by the speed of erosion in the bottom layer.

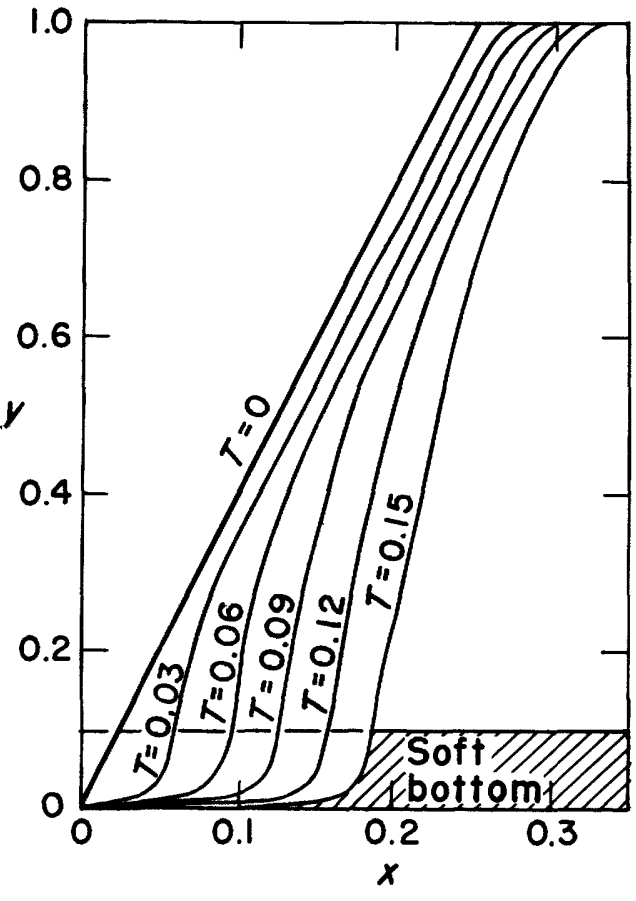

Figure 5. -Graph showing slope with soft bottom.

\section{SLOPE WITH PORE WATER PRESSURE}

A final modification was made in the calculation procedure by setting

$$
a=1-0.9 y
$$

This represents a slope in which the resistance to erosion varies linearly from bottom to top; at the bottom it is lowest, at

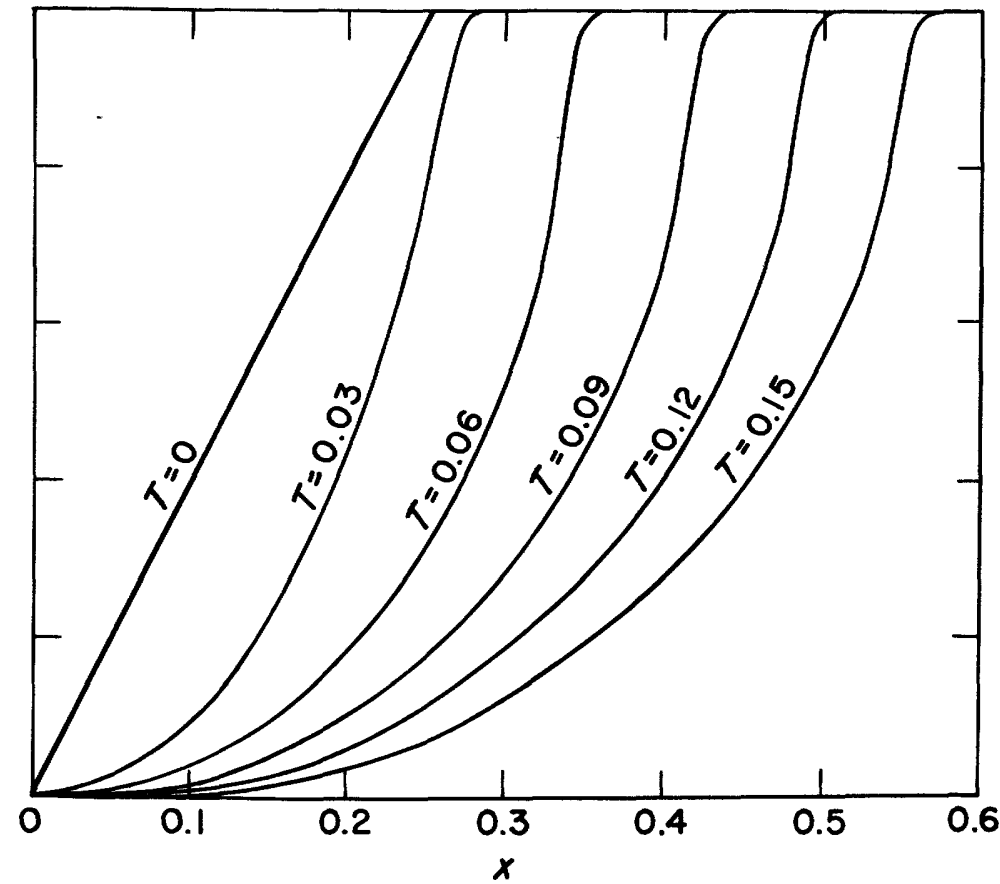

Figure 6.-Graph showing slope with pore water pressure.

Table 5.-Slope with soft bottom

\begin{tabular}{ccccccc}
\hline$x$ & $T=0$ & $T=0.03$ & $T=0.06$ & $T=0.09$ & $T=0.12$ & $T=0.15$ \\
\hline 0.00 & 0 & 0 & 0 & 0 & 0 & 0 \\
.02 & .080 & .0030 & 0 & 0 & 0 & 0 \\
.04 & .16 & .015 & .0025 & 0 & 0 & 0 \\
.06 & .24 & .10 & .0092 & .0019 & 0 & 0 \\
.08 & .32 & .25 & .024 & .0065 & .0015 & 0 \\
.10 & .40 & .35 & .17 & .016 & .0048 & .0012 \\
.12 & .48 & .43 & .34 & .47 & .011 & .0037 \\
.14 & .56 & .51 & .46 & .28 & .025 & .0086 \\
.16 & .64 & .59 & .54 & .44 & .15 & .017 \\
.18 & .72 & .67 & .62 & .56 & .35 & .045 \\
.20 & .80 & .75 & .70 & .65 & .53 & .25 \\
.22 & .88 & .83 & .78 & .73 & .67 & .45 \\
.24 & .96 & .91 & .86 & .81 & .76 & .63 \\
.26 & 1.00 & .98 & .94 & .89 & .84 & .77 \\
.28 & 1.00 & 1.00 & 1.00 & .97 & .92 & .87 \\
.30 & & 1.00 & 1.00 & 1.00 & .99 & .95 \\
.32 & & & & 1.00 & 1.00 & 1.00 \\
.34 & & & & & 1.00 & 1.00 \\
\hline
\end{tabular}


Table 6. - Slope with pore water pressure

\begin{tabular}{|c|c|c|c|c|c|c|}
\hline$x$ & $T=0$ & $T=0.03$ & $T=0.06$ & $T=0.09$ & $\mathrm{~T}=0.12$ & $T=0.05$ \\
\hline 0.00 & 0 & 0 & 0 & 0 & 0 & 0 \\
\hline .02 & .080 & .0030 & 0 & 0 & 0 & 0 \\
\hline .04 & .16 & .014 & .0025 & 0 & 0 & 0 \\
\hline .06 & .24 & .034 & .0090 & .0019 & 0 & 0 \\
\hline .08 & .32 & .062 & .020 & .0063 & .0015 & 0 \\
\hline .10 & .40 & .098 & .036 & .014 & .0047 & .0012 \\
\hline .12 & .48 & .14 & .057 & .026 & .011 & .0036 \\
\hline .14 & .56 & .20 & .082 & .040 & .019 & .0080 \\
\hline .16 & .64 & .26 & .11 & .058 & .031 & .015 \\
\hline .18 & .72 & .34 & .15 & .080 & .045 & .024 \\
\hline .20 & .80 & .44 & .19 & .10 & .061 & .035 \\
\hline .22 & .88 & .57 & .24 & .13 & .081 & .049 \\
\hline .24 & .96 & .73 & .29 & .17 & .10 & .065 \\
\hline .26 & 1.00 & .92 & .36 & .20 & .13 & .083 \\
\hline .28 & 1.00 & 1.00 & .43 & .24 & .16 & .10 \\
\hline .30 & & 1.00 & .53 & .29 & .19 & .13 \\
\hline .32 & & 1.00 & .67 & .34 & .22 & .1 .5 \\
\hline .34 & & 1.00 & .94 & .41 & .26 & .18 \\
\hline .36 & & & 1.00 & .48 & .30 & .21 \\
\hline .38 & & & 1.00 & .57 & .35 & .25 \\
\hline .40 & & & 1.00 & .71 & .41 & .28 \\
\hline .42 & & & 1.00 & .95 & .48 & .33 \\
\hline .44 & & & & 1.00 & .55 & .37 \\
\hline .46 & & & & 1.00 & .66 & .43 \\
\hline .48 & & & & 1.00 & .83 & .49 \\
\hline .50 & & & & 1.00 & 1.00 & .56 \\
\hline .52 & & & & & 1.00 & .65 \\
\hline .54 & & & & & 1.00 & .80 \\
\hline .56 & & & & & 1.00 & .99 \\
\hline .58 & & & & & 1.00 & 1.00 \\
\hline
\end{tabular}

the top highest. This condition could be correlated with the possibility of the slope being water soaked. Then, one might argue that the erodability of the material varies just in the manner indicated.

The results of the calculations are shown numerically in table 6 and graphically in figure 6. It is seen that the slope development is intermediate between that of a slope with caprock and that of a slope with soft bottom, just as would be expected.

\section{REFERENCES}

Scheidegger, A. E., 1961 : Mathematical models of slope development: Geol. Soc. America Bull., v. 72, p. 37-50.

1962 , Some modifications of the slope development problem: Royal Astron. Soc. Geophys. Jour., v. 7, p. 40-53.

Wolman, M. G., 1963, Review of "Theoretical Geomorphology": Geograph. Rev., v. 53, no. 2, p. 331 . 